\title{
Effect of Carbamazepine on Serum Cholesterol and Atherogenic Ratios in Young Adults with Epilepsy
}

\author{
KAWSAR MJ ${ }^{1}$, BHUIYAN M² ${ }^{2}$ BARMAN KK ${ }^{3}$, ISLAM MR ${ }^{4}$, RAHMAN HZ ${ }^{5}$, HANNAN MA $^{6}$, \\ RIZVI AN ${ }^{7}$, REFAYET CNH ${ }^{8}$, RAHAMAN H $^{9}$, MOHAMMOD $\mathrm{RH}^{10}$
}

\begin{abstract}
:
Background: Epilepsy is a common chronic neurological disorder worldwide. Carbamazepine is one of the most commonly used antiepileptic drugs. It is a hepatic cytochrome $P 450$ enzyme inducer which is thought to cause alteration of serum lipids. Objective: To evaluate the effect of carbamazepine on serum cholesterol and atherogenic ratios in young adult epileptic patients. Materials and methods: This prospective study was conducted in the epilepsy clinic and Neurology OPD of Bangabandhu Sheikh Mujib Medical University (BSMMU), Dhaka, from December, 2017 to March, 2019. A total fifty seven newly diagnosed epileptic patients fulfilling the study criteria were studied. Serum TC, HDL-C, TG was measured by using Beckman CoulterAU680 analyzer machine and $L D L-C$ was calculated according to the Friedewald formula in the laboratory of Department of Biochemistry, BSMMU. Results: The mean ( $\pm S D$ ) serum TC, LDL, TG, TC/HDL-C and LDL-C/HDL-C were significantly increased ( $p$-value $<0.001)$ at 3 months of carbamazepine therapy in comparison to the baseline levels. The mean $( \pm S D)$ serum $H D L$ was decreased at 3 months of therapy which was not statistically significant ( $p$-value: 0.135 ). Conclusion: Carbamazepine caused significant rise in serum TC, LDL-C, TG and atherogenic ratios (TC/HDL-C, LDL-C/HDL-C), and insignificant reduction in the serum HDL-C level after three months of therapy.
\end{abstract}

Key words: Epilepsy, Carbamazepine, Total cholesterol (TC), Low density lipoprotein cholesterol (LDL-C), High density lipoprotein cholesterol (HDL-C), Atherogenic ratio etc.

\section{Introduction:}

Epilepsy is a disorder of the brain characterized by an enduring predisposition to generate epileptic seizures and by the neurobiologic, cognitive, psychological, and social consequences of this condition ${ }^{1}$. It is considered to be one of the commonest and frequently encountered neurological conditions that impose the heavy burden on individuals, families, and also on healthcare systems. It is a global health care issue affecting about 50-70 million people worldwide and nearly $80 \%$ of cases live in the developing countries. The worldwide annual incidence and prevalence of epilepsy is 50 in 100000 and 700 in 100000 , respectively. About 2.4 million people are diagnosed with epilepsy each year ${ }^{2}$. It is estimated that there are about 1.5 to 2.0 million epilepsy patients in Bangladesh ${ }^{3}$. Epileptic seizures are the result of excessive and abnormal cortical nerve cell activity in the brain ${ }^{1}$.

1. Dr. Md. Jafrul Kawsar, Phase-B resident, Department of Neurology, Bangabandhu Sheikh Mujib Medical University (BSMMU), Dhaka.

2. Prof.Md. Moniruzzaman Bhuiyan, Professor, Department of Neurology, BSMMU, Dhaka.

3. Dr.Kanuj Kumar Barman, Associate Professor, Department of Neurology, BSMMU, Dhaka.

4. Prof. Md. Rafiqul Islam, Professor and Chairman, Department of Neurology, BSMMU, Dhaka.

5. Prof.Hasan Zahidur Rahman, Professor, Department of Neurology, BSMMU, Dhaka.

6. Prof.M.A. Hannan, Professor, Department of Neurology, BSMMU, Dhaka.

7. Prof.Abu Nasir Rizvi, Professor, Department of Neurology, BSMMU, Dhaka.

8. Dr.Chowdhury Neamul Hassan Refayet, Phase-B resident, Neurology, Department of Neurology, BSMMU, Dhaka.

9. Dr.Habibur Rahaman, Phase-B resident, Neurology, Department of Neurology, BSMMU, Dhaka.

10. Dr. Rakib Hasan Mohammod, Final Part Student, MD (Neurology), Dept. of Neurology,BSMMU,Dhaka. 
Seizure can be classified as generalized, focal and unknown onset ${ }^{4}$. The mainstay of treatment of epilepsy is antiepileptic drugs (AEDs). The choice of AEDs depends upon seizure type, epilepsy syndrome, comorbidities, other medications used, and the patient's age, lifestyle and socioeconomic conditions ${ }^{5}$. Carbamazepine (CBZ) is widely used as a drug of first choice in focal seizure and secondary generalized seizure 6 . It is a less costly, effective and well tolerated drug for seizure control in context of Bangladesh ${ }^{7}$. CBZ is metabolized in the liver. It induces hepatic microsomal cytochrome P450 enzymes, leading to alterations in the metabolism of bile acids, cholesterol, other lipids, bilirubins, and many other endogenous molecules and exogenous drugs ${ }^{8}$. The exact mechanism of alteration of serum cholesterol is not confirmed, but several possible mechanisms are conceivable. CBZ increases the activity of the hepatic cytochrome P450 system, which is involved in synthesis and metabolism of cholesterol $^{9}$. CBZ might compete with the cholesterol in the utilization of hepatic cytochrome P450 enzymes, and this competition could lead to a reduction in the transformation of cholesterol in to bile acids. Thus, reduced cholesterol biotransformation increases total serum cholesterol levels ${ }^{10}$. CBZ also has marked proteinbinding activity that typically causes reduced levels of Thyroxine $\left(\mathrm{T}_{4}\right)$ and free Thyroxine $\left(\mathrm{FT}_{4}\right)$. Reduced thyroxin level causes disinhibition of the rate limiting activity of HMG-CoA reductase, decrease LDL-receptor's activity, resulting in decreased catabolism of LDL and IDL. Thereby, serum total cholesterol, LDL-C levels are increased ${ }^{11}$. Therefore, the aim of the present study was to evaluate any alteration of the serum total cholesterol and atherogenic ratios in newly diagnosed young adult epileptic patients three months after carbamazepine therapy.

\section{Materials and methods:}

It was a longitudinal prospective study, conducted in the Epilepsy clinic of Department of Neurology, Bangabandhu Sheikh Mujib Medical University, Dhaka. Following a predefined protocol, a total seventy newly diagnosed young adult (19-40 years) epileptic patients of both sexes having focal or secondary generalized seizures were enrolled as study population. The patients were diagnosed by history, clinical examination, EEG and relevant investigations like CT scan / MRI of the brain. Their diagnosis was screened and supervised by concerned neurologists at epilepsy clinic. A semistructured questionnaire was developed in English. Approval from the Institutional Review Board (IRB) of BSMMU was obtained prior to the commencement of this study. Atherogenic ratios were calculated as TC/HDL-C and LDL-C/HDL-C. Patients were started on carbamazepine at minimal effective dose $100 \mathrm{mg} 12$ hourly and dose was titrated gradually upto the dose at which the seizure was controlled. Patients were informed about the possible common side effects of carbamazepine. Patients were monitored monthly for assessment of clinical response, any side effect of drug and drug compliance. Another fasting serum lipid profile was done at 3 months of CBZ therapy as per standard procedure. All other relevant investigations of all patients were done in the respective department of BSMMU, Dhaka. At the end of data collection, all the data were rechecked, coded and entered in the standard statistical software, data base using SPSS software (Version25). Continuous variable was expressed as Mean \pm SD. Categorical variable was presented by frequency and percentage. Paired student's t test was used to compare mean of various parameters of serum lipids at baseline and at 3 months of carbamazepine therapy. Unpaired t-test was used for comparison of changes of lipid parameters between male and female patients. The correlation of changes of parameters of serum lipids and atherogenic ratios with age, BMI, dose of carbamazepine was determined by the Pearson's correlation coefficient test. $P$ value $<0.05$ was considered as statistically significant. All statistical analysis was done by SPSS software windows version 25 .

\section{Results and observation}

A total fifty-seven young adult patients fulfilling the inclusion and exclusion criteria were finally assessed in this study. The study results were as followed: 
Table-I

Distribution of the study population according to different age range $(n=57)$

\begin{tabular}{lcc}
\hline Age of patient /yrs & Total number & Percentage $\%$ \\
\hline $19-25$ yrs & 30 & 52.6 \\
$26-30$ yrs & 16 & 28.1 \\
$31-40$ yrs & 11 & 19.3 \\
Total & 57 & 100.0 \\
Mean \pm SDRange & $25.7 \pm 6.1719-40$ & \\
\hline
\end{tabular}

Table I showing the mean age of the patients was $25.7 \pm 6.17$ years. The most frequent age group was $19-25$ years representing $52.6 \%$ followed by $28.1 \%$ in $26-30$ years.

Table-II

Distribution of the study population according to dose of carbamapezine at 3 months of therapy $(n=57)$

\begin{tabular}{|c|c|c|}
\hline Dose & Frequency & Percentage (\%) \\
\hline$<10 \mathrm{mg} / \mathrm{kg} / \mathrm{day}$ & 22 & 38.6 \\
\hline $10-15 \mathrm{mg} / \mathrm{kg} /$ day & 30 & 52.6 \\
\hline$>15$ mg/kg/day & 5 & 8.8 \\
\hline Total & 57 & 100.0 \\
\hline Dose (mg/kg/day) (Mean $\pm S D)$ & \multicolumn{2}{|c|}{$10.81 \pm 2.78$} \\
\hline Range & \multicolumn{2}{|c|}{$5.97-17.14$} \\
\hline Dose (mg/day) (Mean \pm SD) & \multicolumn{2}{|c|}{$628.1 \pm 186.8$} \\
\hline Range & \multicolumn{2}{|c|}{$400-1200$} \\
\hline
\end{tabular}

Table-III

Comparison of mean levels of serum TC, LDL-C, HDL-C, TG at baseline and at 3 months of carbamazepine therapy $(n=57)$

\begin{tabular}{lccc}
\hline Parameter & Baseline $(\mathrm{n}=57)$ & At 3 months $(\mathrm{n}=57)$ & $P$ value \\
& Mean \pm SD & Mean \pm SD & \\
\hline TC $(\mathrm{mg} / \mathrm{dl})$ & $147.2 \pm 22.1$ & $163.1 \pm 25.4$ & $<0.001^{\mathrm{s}}$ \\
LDL-C $(\mathrm{mg} / \mathrm{dl})$ & $82.2 \pm 20.5$ & $96.8 \pm 23.1$ & $<0.001^{\mathrm{s}}$ \\
HDL-C $(\mathrm{mg} / \mathrm{dl})$ & $46.6 \pm 6.6$ & $45.0 \pm 8.2$ & $0.135^{\mathrm{ns}}$ \\
TG $(\mathrm{mg} / \mathrm{dl})$ & $92.1 \pm 27.5$ & $106.8 \pm 31.5$ & $<0.001^{\mathrm{s}}$ \\
\hline
\end{tabular}

Paired t-test was done as a test of significance and $p$-value $<0.05$ was considered as significant.s=significant, ns $=$ non-significant

Table-IV

Comparison of atherogenic ratios at baseline and at 3 months of carbamazepine therapy $(n=57)$

\begin{tabular}{lccc}
\hline Parameter & $\begin{array}{c}\text { Baseline }(\mathrm{n}=57) \\
\text { Mean } \pm S D\end{array}$ & $\begin{array}{c}\text { At } 3 \text { months }(\mathrm{n}=57) \\
\text { Mean } \pm S D\end{array}$ & $P$ value \\
\hline TC/HDL-C & $3.19 \pm 0.61$ & $3.73 \pm 0.81$ & $<0.001^{\mathrm{s}}$ \\
LDL-C/HDL-C & $1.84 \pm 0.53$ & $2.23 \pm 0.70$ & $<0.001^{\mathrm{s}}$ \\
\hline
\end{tabular}


Table-V

Correlation of age and BMI of patients; dose of carbamazepine at three months with percentage change of serum TC, HDL, LDL, TC/HDL, LDL/HDL.

\begin{tabular}{|c|c|c|c|c|c|c|}
\hline \multirow[t]{2}{*}{ Variables } & \multicolumn{2}{|c|}{ Age } & \multicolumn{2}{|c|}{$\mathrm{BMI}$} & \multicolumn{2}{|c|}{ Dose (per kg/day) } \\
\hline & r-value & p-value & r-value & $\mathrm{p}$-value & r-value & $p$-value \\
\hline Change of TC (mg/dl) & 0.152 & 0.260 & $0.278^{\text {sn }}$ & 0.036 & 0.241 & 0.071 \\
\hline Change of HDL-C $(\mathrm{mg} / \mathrm{dl})$ & -0.016 & 0.903 & 0.172 & 0.200 & -0.015 & 0.91 \\
\hline Change of LDL-C (mg/dl) & 0.191 & 0.154 & 0.147 & 0.276 & 0.145 & 0.283 \\
\hline Change of TG (mg/dl) & -0.022 & 0.870 & 0.103 & 0.447 & 0.113 & 0.402 \\
\hline Change of TC/HDL & 0.129 & 0.340 & -0.001 & 0.991 & 0.095 & 0.482 \\
\hline Change of LDL-C/HDL-C & 0.077 & 0.569 & -0.064 & 0.636 & 0.088 & 0.513 \\
\hline
\end{tabular}

Pearson's correlation coefficient test was done as a test of correlation. p- value $<0.05$ was considered as significant, $r$ - value signified the strength of correlation.

\section{Discussion:}

Carbamazepine is a commonly used antiepileptic drug in the treatment of focal and secondary generalized seizure. It is a hepatic microsomal enzyme inducer, and thought to alter the metabolism of lipids even in the early course of therapy. Several studies have reported significant increase in serum total cholesterol (TC) and LDL$\mathrm{C}$ following carbamazepine therapy. But, the controversy regarding the influence of carbamazepine on serum HDL-C, and atherogenic ratios (TC/HDL-C, LDL-C/HDL-C) is still remained unsettled. However, the alteration in serum lipids may cause development of atherosclerotic vascular diseases in epileptic patients taking carbamazepine. This prospective longitudinal study was carried out in the epilepsy clinic, OPD of Neurology, BSMMU, Dhaka, with the primary aim to evaluate the effect of carbamazepine on serum cholesterol and atherogenic ratios in young adults with epilepsy. In this study, some demographic profile like age, sex, BMI of patients; seizure types; dose of carbamazepine and their correlation with the changes of different parameters of lipids were also assessed. In this study, seventy newly diagnosed or untreated epileptic patients fulfilling the study criteria during the study period (December, 2017 to March, 2019) were enrolled. However, thirteen of these patients did not return for follow-up visits, and the study was completed with fifty-seven patients. Among the thirteen dropped out patients, three developed mild hypersensitivity reaction in the form of itching, urticaria and discontinued the drug.A total fiftyseven young adult patients ranging from 19 to 40 years of age were finally assessed in this study. The mean $( \pm S D)$ age of the patients was found to be $25.7 \pm 6.17$ years. It was observed that majority of the patients $30(52.6 \%)$ were in $19-25$ years age group. Mian et al., (2016) ${ }^{3}$ conducted a study on demographic profiles of epileptic patients in Bangladesh, where they found that the most of the epileptic patients were younger ( $<30$ years) in the study population. The mean age of case (uncontrolled seizure) and control (controlled seizure) groups were $21.84 \pm 8.70$ and $23.94 \pm$ 10.28 years respectively. In this present study, among fifty-seven patients male were $36(63.2 \%)$ and female were $21(36.8 \%)$ and male female ratio was 1.7:1. It was observed that male were predominant among the epileptic patients which was $63.2 \%$ of the study population. Mian et al., $(2016)^{3}$ found that the male $31(62 \%)$ was predominant than female $19(38 \%)$ among 50 Bangladeshi epileptic patients in case group. Aggarwal et al., (2009) ${ }^{13}$ conducted a prospective study among 29 children where male were 16 $(55 \%)$ and female were (45\%). These studies were convenient to our current study in respect of sex. This present study showed that patients with focal to bilateral convulsive seizure (Secondary generalized seizure) was 35 (61.4\%), focal seizure 
with impaired awareness (complex partial seizure) was $13(22.8 \%)$ and focal seizure with intact awareness (simple partial seizure) was 9 (15.8\%). The seizure pattern of our study population was compatible with a previous study done by Habib et al., $(2013)^{7}$ in Bangladesh. Habib et al., (2013) $)^{7}$ reported that among the patients with focal seizure $67 \%$ was secondary generalized seizure, $22 \%$ was complex partial seizure and $11 \%$ was simple partial seizure. In the present study, the mean $( \pm S D)$ dose of carbamazepine at three months was $10.81 \pm$ $2.78 \mathrm{mg} / \mathrm{kg} /$ day $(628.1 \pm 186.8 \mathrm{mg} /$ day $)$. The maximum patients $30(52.6 \%)$ took carbamazepine at a dose of $10-15 \mathrm{mg} / \mathrm{kg} /$ day. The $38.6 \%$ of patients took carbamazepine at a dose of $<10 \mathrm{mg} /$ $\mathrm{kg} /$ day, whereas only $8.8 \%$ of patients got carbamazepine at $>15 \mathrm{mg} / \mathrm{kg} /$ day. The daily dose of carbamazepine ranged 400-1200 mg/day (5.97 - $17.14 \mathrm{mg} / \mathrm{kg} /$ day). The dose of CBZ was compatible to the mean dose $(10.3 \pm 1.1 \mathrm{mg} / \mathrm{kg} /$ day) in a previous study done by Aggarwal et al., $(2009)^{13}$. In another case-control study conducted by Aggarwal et al., $(2004)^{14}$ the mean dose of CBZ was $13.1 \pm 3.5 \mathrm{mg} / \mathrm{kg} / \mathrm{day}$. These studies were compatible with the current study in respect of dose of carbamazepine.In this current study the baseline levels of serum TC, HDL-C, LDL-C, TG and atherogenic ratios (TC/ HDL-C, LDL- HDL), were compared to their levels at 3 months of CBZ therapy. Results showed that mean $( \pm S D)$ serum TC at baseline was $147.2 \pm 22.1 \mathrm{mg} / \mathrm{dl}$ and at 3 months after carbamazepine therapy was $163.1 \pm$ $25.4 \mathrm{mg} / \mathrm{dl}$. A significant increase in serum TC was found ( $p$-value $<0.001$ ) at 3 months of treatment in comparison to baseline level. The mean $( \pm S D)$ serum LDL-C was significantly increased from 82.2 $\pm 20.5 \mathrm{mg} / \mathrm{dl}$ to $96.8 \pm 23.1 \mathrm{mg} / \mathrm{dl}$ ( $p$-value $<0.001$ ). These results were supported by several studies done around the world such as Aggarwal et al., $(2009)^{13}$, Mahmoudian et al., (2004) ${ }^{15}$, Bramswig et al., (2003) $)^{12}$.Bramswig et al., (2003) ${ }^{12}$ showed that TC and LDL-C levels significantly increased from $190 \pm 30 \mathrm{mg} / \mathrm{dl}$ to $209 \pm 25 \mathrm{mg} / \mathrm{dl}(\mathrm{p}<0.006)$ and from $126 \pm 27 \mathrm{mg} / \mathrm{dl}$ to $142 \pm 25 \mathrm{mg} / \mathrm{dl}(\mathrm{p}<$ 0.011 ), respectively. Aggarwal et al., $(2009)^{13}$ found that the mean $( \pm S D)$ serum TC significantly increased from baseline $130.6 \pm 27.3 \mathrm{mg} / \mathrm{dl}$ to
$144.7 \pm 32.9 \mathrm{mg} / \mathrm{dl}$ at three months of therapy (pvalue $<0.018$ ). The LDL-C was also significantly increased from $72.3 \pm 24.6 \mathrm{mg} / \mathrm{dl}$ to $86.6 \pm 30.6$ $\mathrm{mg} / \mathrm{dl}$ ( $p$-value $<0.016)$. These findings were convenient to our present study. In this study, the mean $( \pm S D)$ serum TG level was $92.1 \pm 27.5 \mathrm{mg} /$ $\mathrm{dl}$ and $106.8 \pm 31.5 \mathrm{mg} / \mathrm{dl}$ at baseline and at 3 months respectively. Serum TG levels increased significantly after carbamazepine therapy in comparison to the pretreatment levels ( $p$-value < 0.001). Bramswig et al., (2003) ${ }^{12}$ reported the significant rise of mean serum TG from $95 \pm 39$ $\mathrm{mg} / \mathrm{dl}$ at baseline to $107 \pm 37 \mathrm{mg} / \mathrm{dl}$ at three months of therapy ( $p$-value $<0.025$ ) which supported the present study result. Regarding the changes of serum HDL level, this current study showed that mean $( \pm S D)$ serum HDL levels were $46.6 \pm 6.6$ $\mathrm{mg} / \mathrm{dl}$ and $45.0 \pm 8.2 \mathrm{mg} / \mathrm{dl}$ at baseline and at 3 months respectively. The mean HDL-C level reduced at 3 months after carbamazepine therapy in comparison to baseline level which was statistically not significant ( $p$-value: 0.135 ). This study result was compatible to a study conducted by Aggarwal et al., $(2009)^{13}$, where the mean HDLC level was $44.3 \pm 15.1 \mathrm{mg} / \mathrm{dl}$ and $42.2 \pm 13.0 \mathrm{mg} /$ $\mathrm{dl}$ at baseline and at three months respectively. The decreased level of HDL-C was not statistically significant (p-value: 0.243). Nikolaos et al., (2004) ${ }^{10}$ conducted a case control study among adults showing a significantly ( $p$-value $<0.001$ ) higher HDL-C $(57.8 \pm 5.0 \mathrm{mg} / \mathrm{dl})$ in CBZ group than control group $(52.4 \pm 6.8 \mathrm{mg} / \mathrm{dl})$. These contradictory study results might be due to different study design, age, dietary habits, racial factor and duration of carbamazepine therapy. There were very few prospective studies, whereas most of the studies were cross sectional and a variety of different control groups were used for comparison. Regarding the changes in atherogenic ratios (TC/ $\mathrm{HDL}, \mathrm{LDL} / \mathrm{HDL}$ ) the present study showed significant increase ( $p$-value $<0.001)$ in the mean $( \pm S D)$ of TC/HDL and LDL/HDL. The mean $( \pm S D)$ of TC/HDL at baseline and at 3 months were 3.19 \pm 0.61 and $3.73 \pm 0.81$ respectively. The mean $( \pm S D)$ of LDL-C/HDL-C were $1.84 \pm 0.53$ and 2.23 \pm 0.70 at baseline and at 3 months respectively. This study result was supported by previous studies 
conducted by Aggarwal et al., (2009) ${ }^{13}$, Mahmoudian et al., (2005) $)^{15}$. Aggarwal et al., $(2009)^{13}$ showed that the mean \pm (SD) TC/HDL significantly ( $p$-value-0.001) increased from $3.1 \pm$ 0.86 at baseline to $3.7 \pm 1.1$ at 3 months of therapy. That study also revealed significant rise ( $p$-value < 0.018 ) of mean LDL/ HDL from $1.8 \pm 0.7$ at baseline to $2.2 \pm 0.9$ at three months of therapy. The present study showed that there was no significant correlation of changes of TC, LDL-C, HDL-C, TG and atherogenic ratios (TC/HDL-C, LDL-C/HDL$\mathrm{C})$ with age, sex, BMl and dose of carbamazepine. Nikolaos et al., $(2004)^{10}$ reported no significant correlations between changes in serum lipid levels and age, sex, BMI of the epileptic patients, which was convenient to the current study. The mean changes of TC, LDL-C, HDL-C, TG and atherogenic ratios between male and female were not significantly different. The mean $( \pm S D)$ changes of TC and TG in female were greater than male which was not statistically significant ( $p$-value: $0.951,0.259)$. The correlation of changes of cholesterol and atherogenic ratios with the dose of carbamazepine were not significant in this present study. Several studies like Bramswig et al., $(2002)^{16}$, Aggarwal et al., (2009) $)^{13}$ also found no significant correlation of changes of parameters of serum lipids with dose and plasma concentration of carbamazepine which was convenient to the results of current study. The present study revealed that carbamazepine caused significant rise of serum TC, LDL, TG levels and atherogenic ratios (TC/HDL-C, LDL-C/HDL-C) at three months of therapy. The reduction of serum HDL-C at three months of therapy was not significant. There was no significant correlation of age, sex, BMI of patients and dose of carbamazepine with the changes of serum cholesterol and atherogenic ratios at three months of therapy. The present study revealed that carbamazepine caused significant rise of serum TC, LDL, TG levels and atherogenic ratios (TC/HDL-C, LDL-C/HDL-C) at three months of therapy. The reduction of serum HDL-C at three months of therapy was not significant. There was no significant correlation of age, sex, BMI of patients and dose of carbamazepine with the changes of serum cholesterol and atherogenic ratios at three months of therapy.

\section{Conclusion:}

The present study revealed that carbamazepine caused significant rise of serum TC, LDL, TG levels and atherogenic ratios (TC/HDL-C, LDL-C/HDLC) at three months of therapy. The reduction of serum HDL-C at three months of therapy was not significant. So, those patients who are taking carbamazepine are prone to develop dyslipidemia, even in the early course of treatment.

\section{Limitations:}

Our study was done in short period, with a small sample size. Serum carbamazepine level was not measured, and the correlation of serum carbamazepine level with the changes of lipid parameters could not be evaluated.

\section{Recommendations:}

Patients taking carbamazepine should be warned about the possibility of developing dyslipidemia, and dyslipidemia associated cardiovascular and other atherosclerotic diseases. Lipid profile should be monitored routinely during carbamazepine therapy in epileptic patients. Pharmacological and nonpharmacological measures including adequate dietary advice, regular exercise can be suggested to avoid dyslipidemia. Further studies can be conducted to solve the controversy regarding the alteration of HDL-C level and the exact mechanism.

\section{References:}

1. Fisher RS, Boas WV, Blume W, Elger C, Genton P, Lee P, Engel Jr J. Epileptic seizures and epilepsy: definitions proposed by the International League Against Epilepsy (ILAE) and the International Bureau for Epilepsy (IBE). Epilepsia. 2005 Apr;46(4):470-2.

2. Trinka E, Kwan P, Lee B, Dash A. Epilepsy in Asia: Disease burden, management barriers, and challenges. Epilepsia. 2019 Mar; 60: 7-21.

3. Mian MF, Jobayer M, Afroz Z, Chowdhury AH, Chowdhury RN, Habib M, Mohammad QD. Demographic proles of epileptic patients and their awareness towards epilepsy with the inuence on compliance. Bangladesh Medical Journal. 2016 Jul 30; 45(1):20-4. 
4. Fisher RS, Cross JH, French JA, Higurashi N, Hirsch E, Jansen FE, Lagae L, Moshé SL, Peltola J, Roulet Perez E, Scheffer IE. Operational classification of seizure types by the International League against Epilepsy: Position Paper of the ILAE Commission for Classification and Terminology. Epilepsia. 2017 Apr; 58(4):522-30.

5. Azar NJ, Abou-Khalil BW. Considerations in the choice of an antiepileptic drug in the treatment of epilepsy. InSeminars in neurology 2008 Jul (Vol. 28, No. 03, pp. 305-316). () Thieme Medical Publishers.

6. Karceski S, Morrell MJ, Carpenter D. Treatment of epilepsy in adults: expert opinion, 2005. Epilepsy \& Behavior. 2005 Sep $1 ; 7: 1-64$.

7. Habib M, Khan SU, Hoque MA, Mondal MB, Hasan AH, Chowdhury RN, Haque B, Rahman KM, Chowdhury AH, Ghose SK, Mohammad QD. Antiepileptic drug utilization in Bangladesh: experience from Dhaka Medical College Hospital. BMC research notes. 2013 Dec; 6(1):473.

8. Chen J, Zhao KN, Chen C. The role of CYP3A4 in the biotransformation of bile acids and therapeutic implication for cholestasis. Annals of translational medicine. 2014 Jan;2(1).

9. LoPinto-Khoury C, Mintzer S. Antiepileptic drugs and markers of vascular risk. Current treatment options in neurology. $2010 \mathrm{Jul} \mathrm{1;}$ 12(4):300-8.

10. Nikolaos T, Stylianos G, Chryssoula N, Irini $P$, Christos M, Dimitrios T, Konstantinos P, Antonis T. The effect of long-term antiepileptic treatment on serum cholesterol (TC, HDL, and LDL) and triglyceride levels in adult epileptic patients on monotherapy. Medical Science Monitor. 2004 Apr 1; 10(4):MT50-2.

11. Verrotti A, Laus M, Scardapane A, Franzoni $\mathrm{E}$, Chiarelli $\mathrm{F}$. Thyroid hormones in children with epilepsy during long-term administration of carbamazepine and valproate. European journal of endocrinology. 2009 Jan 1; 160(1):81-6.

12. Brämswig $S$, Sudhop $T$, Luers $C$, Von Bergmann K, Berthold HK. Lipoprotein (a) concentration increases during treatment with carbamazepine. Epilepsia. 2003 Mar;44(3):457-60.

13. Aggarwal, A., Singh, V., Batra, S., Faridi, M.M.A. and Sharma, S. Effect of carbamazepine therapy on serum lipids in children with partial epilepsy. Pediatric neurology. 2009;40(2):94-97.

14. Aggarwal A, Kumar M, Faridi MM. Effect of carbamazepine on serum lipids and liver function tests. Age (yr). 2005 Sep 1;8(2.8):836.

15. Mahmoudian T, Iranpour R, Messri N. Serum lipid levels during carbamazepine therapy in epileptic children. Epilepsy \& Behavior. 2005 Mar 1; 6(2):257-9.

16. Bramswig S, Kerksiek A, Sudhop T, Luers C, Von Bergmann K, Berthold HK. Carbamazepine increases atherogenic lipoproteins: mechanism of action in male adults. American Journal of Physiology-Heart and Circulatory Physiology. 2002 Feb 1; 282(2):H704-16. 